\title{
Truncated Amplification: A Method for High-Fidelity Template-Driven Nucleic Acid Amplification
}

BioTechniques 33:129-138(July 2002)

\author{
Qiang Liu, Piotr Swiderski, \\ and Steve S. Sommer \\ City of Hope National Medical \\ Center, Duarte, CA, USA
}

can amplify quadratically or geometrically, depending on whether two or one chimeric oligonucleotides are used. Truncated amplification is a promising approach when tem plate-driven amplification is desired to increase the frequency of error-free products.

\section{INTRODUCTION}

The error rate of conventional PCR is problematic when amplifying from single cells or amplifying segments for protein functional analysis by in vitro translation. We describe truncated amplification, a method for high-fidelity amplification in which DNA polymerase errors are not propagated efficiently and original DNA tem plates exert greater influence on the amplification process. Truncated amplification utilizes pairs of oligonucleotides and thermal cycling, but it differs from PCR. Truncated amplification amplifies non-exponentially with one or two chimeric oligonucleotides and produces truncated terminal products that are no more than three rounds of replication from the original template. Exon 6 of the p53 gene was utilized as a model system to demonstrate proof of principle. Chimeric oligonucleotides containing three $3^{\prime} \rightarrow 5^{\prime}$ reverseddeoxynucleotides or 2'-OMe-ribonucleotides at 6-8 nucleotides from the 3' terminus retained sequence specificity and primer extension activity. With $\mathrm{PfuTurbo}^{\mathrm{TM}}$, but not with Taq or Vent (exo-) DNA polymerases, the modified nucleotides completely truncated the DNA polymerase elongation. The resulting truncated terminal products are not templates for further amplification because of the short length of the $3^{\prime}$ complementary region. Truncated amplification
Amplification of nucleic acids is a fundamental tool of molecular medicine. A number of methods for enzymatic nucleic acid amplification in vitro have been developed, such as PCR (21), ligase chain reaction (LCR) (2, $10)$, rolling circle amplification (RCA) $(1,15), Q \beta$ replicase (9), self-sustained sequence replication (3SR) (5), and pyrophosphorolysis-activated polymerization (PAP) (12).

PCR is the most popular method of nucleic acid amplification. PCR is an exponential process, in which the extension products from one cycle of am plification are used as templates for subsequent cycles of amplification (21). LCR and PAP can amplify exponentially $(2,10,12)$; RCA can amplify in a hyperbranching manner (super-exponentially) $(1,15)$.

PCR can routinely achieve an amplification of 10 million-fold. It is an extraordinary tool for making qualitative measurements. However, the exponential nature of amplification creates certain challenges. The DNA polymerase error can be exponentially propagated in amplified products. Allele-dropout and problems in single-cell amplifications DNA polymerase error are significant
(19). In addition, the sensitivity of allele-specific PCR for detecting rare mutations is limited by the exponential am plification of any mismatch extensions.

Here we describe truncated amplification (TA), which generates truncated terminal products that accumulate in a quadratic (TA-q) or geometric (TA-g) manner.

\section{MATERIALS A N D METHODS}

\section{Preparation of Templates by PCR}

Each segment of exon 6 in the human $p 53$ gene $\left(\right.$ GenBank ${ }^{\circledR}$ accession no. X54156, where nucleotide 13287 is assigned as position 1) was amplified by PCR. A 270-bp duplexed segment (DU:UD) of $57.4 \%$ GC content was prepared with primers of $\mathrm{D}=\mathrm{p} 53(-35)$ 30D (5'-GGTGAGCAGCTGGGGCTGGAGAGACGACAG-3') and $\mathrm{U}=\mathrm{p} 53$ (235)30U (5'-CCTACTGCTCACCCG GAGGGCCACTGACAA-3'). A 154 bp segment (RS:SR) was prepared with primers of $\mathrm{R}=\mathrm{p} 53(16) 22 \mathrm{D}$ and $\mathrm{S}=$ p53(170)22U (Table 1). The volume of the reaction is $50 \mu \mathrm{L}$, containing: 50 $\mathrm{mM} \mathrm{KCl}, 10 \mathrm{mM}$ Tris- $\mathrm{HCl}, \mathrm{pH}$ 8.3, 1.5 $\mathrm{mM} \mathrm{MgCl} 2,200 \mu \mathrm{M}$ each of the four dNTPs, $0.1 \mu \mathrm{M}$ each primer, $2 \%$ DMSO, 1 U Taq DNA polymerase (Roche Applied Science, Indianapolis, IN, USA), and $250 \mathrm{ng}$ genomic DNA. Cycling conditions were $94^{\circ} \mathrm{C}$ for $15 \mathrm{~s}$, $55^{\circ} \mathrm{C}$ for $30 \mathrm{~s}$, and $72^{\circ} \mathrm{C}$ for $1 \mathrm{~min}$, for a total of 35 cycles with a GeneAmp ${ }^{\circledR}$ PCR System 9700 (Applied Biosytems, Foster City, CA, USA). The PCR prod- 
uct was purified from primers and other small molecules by approximately 10000 -fold by three rounds of retention on a Centricon ${ }^{\circledR} 100$ microconcentrator (Amicon, Bedford, MA, USA). The amount of recovered PCR product was determined by UV absorbance at $260 \mathrm{~nm}$.

\section{Synthesis of Chimeric Oligonucleotides}

Synthesis of the chimeras (Table 1) was performed on a model 394 DNA/RNA Synthesizer (Applied Biosystems) in a DMT-on mode (4). Extended time (500 s) was used for the coupling of $2^{\prime}$-OMe (C and T)-3'-CEphosphoramidites and $300 \mathrm{~s}$ for $\mathrm{dCBz}$ and $\mathrm{T}$ 5'-CE-phosphoramidites (Glen Research, Sterling, VA, USA). The T, $\mathrm{dC}^{\mathrm{TAC}}, \mathrm{dG}^{\mathrm{TAC}}$, and $\mathrm{dA} \mathrm{A}^{\mathrm{TAC}} 3^{\prime}$-CE-phosphoroamidites and an activator $(0.25 \mathrm{M}$ 4,5-dicyanoimidazole in acetonitrile) were from Proligo (Boulder, CO, USA). The product was cleaved from the resin and deprotected. DMT-on products were separated on preparative PRP-1 (Hamilton, Reno, NV, USA) column. After the removal of DMT, the chimeras were purified by ion-paired HPLC (26). The amount of product was determined by UV absorbance at 260 nm. Purity of the product was confirmed using $32 \mathrm{P}$ radioactive labeling by $\mathrm{T} 4$ kinase and $7 \mathrm{M}$ urea/analytical PAGE in TBE buffer $(90 \mathrm{mM}$ Trisboric acid, $\mathrm{pH} 8.3,1 \mathrm{mM}$ EDTA).

\section{TA}

The duplexed template was amplified with two oligonucleotides. The 25$\mu \mathrm{L}$ reaction mixture contained $20 \mathrm{mM}$ Tris- $\mathrm{HCl}, \mathrm{pH} 8.8,10 \mathrm{mM} \mathrm{KCl}, 10 \mathrm{mM}$ $\left(\mathrm{NH}_{4}\right)_{2} \mathrm{SO}_{4}, 2.0 \mathrm{mM} \mathrm{MgSO}, 250 \mu \mathrm{M}$ each of the four dNTPs, downstream and upstream oligonucleotides (see Table 1 for final concentrations), $0.1 \%$ Triton ${ }^{\circledR} \mathrm{X}-100,0.1 \mathrm{mg} / \mathrm{mL}$ nucleasefree $\mathrm{BSA}, 2 \% \mathrm{DMSO}, 1 \mu \mathrm{Ci}[\alpha-$ 32P]dCTP (3000 Ci/mmol; Amersham Biosciences, Piscataway, NJ, USA), 1 U PfuTurbo ${ }^{\mathrm{TM}}$ DNA polymerase (Stratagene, La Jolla, CA, USA), and 2 ng template. Slightly different conditions were used with 1 U Taq DNA polymerase $(50 \mathrm{mM} \mathrm{KCl}, 10 \mathrm{mM}$ Tris- $\mathrm{HCl}$, $\mathrm{pH} 8.3,1.5 \mathrm{mM} \mathrm{MgCl}_{2}, 200 \mu \mathrm{M}$ each
dNTPs, and no BSA). When $1 \mathrm{U}$ Vent $_{R}{ }^{\circledR}\left(\right.$ exo $\left.^{-}\right)$DNA polymerase (New England Biolabs, Beverly, MA, USA) was used, conditions were identical to those used for PfuTurbo, except BSA was omitted. The cycling conditions were $94^{\circ} \mathrm{C}$ for $20 \mathrm{~s}, 55^{\circ} \mathrm{C}$ for $30 \mathrm{~s}$, and $68^{\circ} \mathrm{C}$ for $2 \mathrm{~min}$, for a total of 20 cycles.

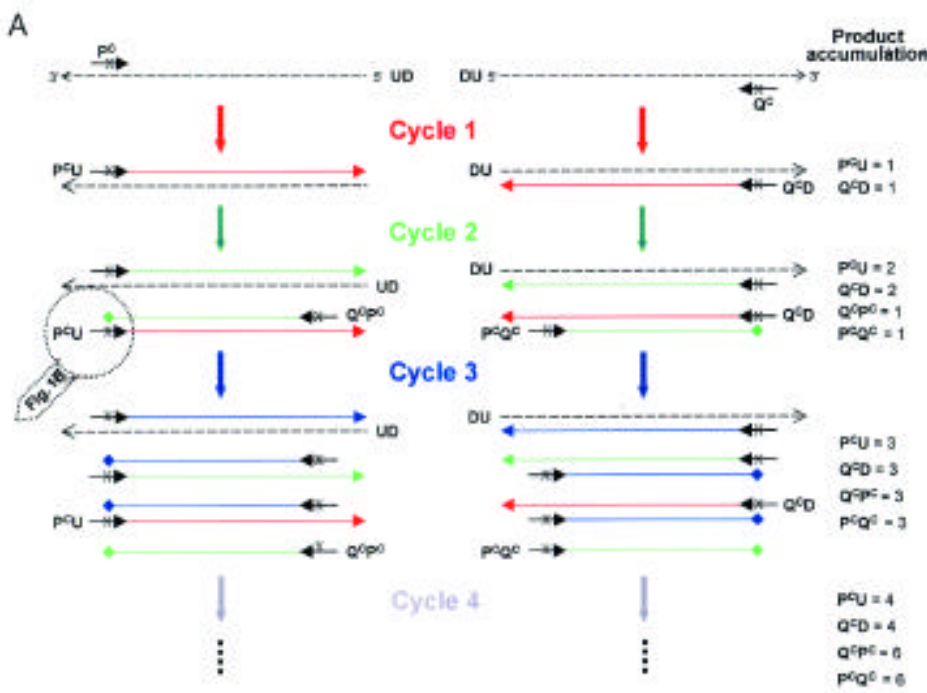

B

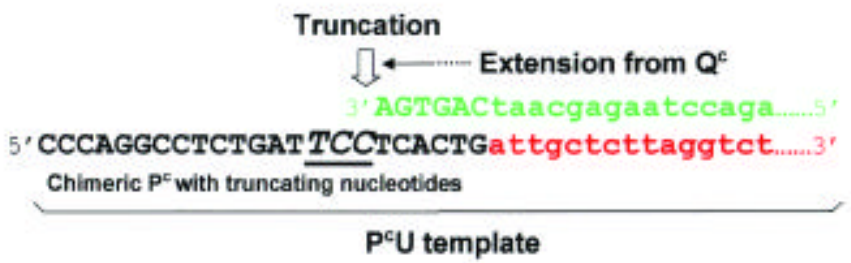

C

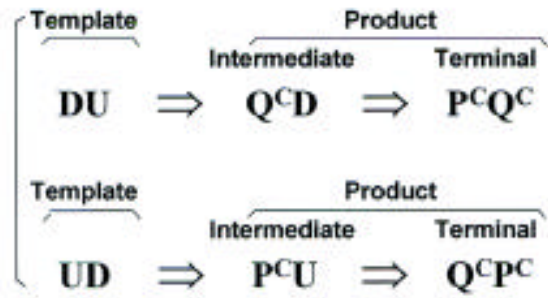

Figure 1. Principle of TA-q. The downstream and upstream strands of the original template are denoted as DU and UD (each 270 bases in the model system), respectively. The truncating chimeric oligonucleotides are $\mathrm{PC}^{\mathrm{C}}$ and $\mathrm{Q}^{\mathrm{C}}$. They are complementary to the UD and DU strands, respectively. (A) Schematic of TA-q. TA-q is performed with both $\mathrm{P}^{\mathrm{C}}$ and $\mathrm{Q}$ chimeric oligonucleotides. The red, green, and blue products are generated in cycles 1, 2, and 3, respectively. Segments $\mathrm{PC}^{\mathrm{C}}$ ( 235 bases) and $\mathrm{QD}$ ( 221 bases) are the non-truncated intermediate products (e.g.,, red products in cycle 1). Segments $\mathrm{P}^{\mathrm{C}} \mathrm{Q}^{\mathrm{C}}$ and $\mathrm{QP}^{\mathrm{C}}$ (each 170 bases) are the truncated terminal products and first appear in cycle 2 . The maximum product accumulations are also shown on the right for each of the first four cycles. By cycle $4, \mathrm{P}^{\mathrm{C}} \mathrm{U}=4, \mathrm{QD}=4, \mathrm{P}^{\mathrm{C}} \mathrm{Q}^{\mathrm{C}}=$ 6 , and $\mathrm{QP}^{\mathrm{C}}=6$. By 40 cycles, $\mathrm{P}^{\mathrm{C}} \mathrm{U}$ or $\mathrm{QP}^{\mathrm{D}}=40$, and $\mathrm{P}^{C} \mathrm{Q}^{\mathrm{C}}$ or $\mathrm{QP}^{\mathrm{C}}=780$. The circled region is detailed in panel B. (B) Detail of truncation event. The segment $\mathrm{PC}^{\mathrm{C}}$ is generated in the first cycle by extending the chimeric $\mathrm{PC}^{\mathrm{C}}$ with the three truncating nucleotides underlined. In the second cycle, chimeric $Q$ is annealed with $\mathrm{P}^{\mathrm{C}} \mathrm{Q}$ as template and is extended. The product $\mathrm{QP}^{\mathrm{C}}$ is truncated because the DNA polymerase is unable to read through the modified nucleotides on the template. The truncated product $\mathrm{QPC}_{\mathrm{P}}$ cannot be used as template for subsequent amplification. (C) Flowchart of TA-q product accumulation. A branch of product accumulation derives from each of the two original single-stranded templates. Four types of products accumulate. Segments $\mathrm{P}^{\mathrm{C}} \mathrm{U}$ (235 bases) and $\mathrm{Q}_{\mathrm{D}}(221$ bases) are the intermediate products that are not truncated and can be used as templates for further amplification. Segments $\mathrm{P}^{C} \mathrm{Q}^{\mathrm{C}}$ and $\mathrm{QPP}^{\mathrm{C}}$ (each 170 bases) are terminal products that are truncated and cannot be amplified further by $\mathrm{Q}_{\text {and }} \mathrm{PC}^{\mathrm{C}}$. 
Table 1. Oligonucleotides

\begin{tabular}{|c|c|c|c|c|c|}
\hline$\#$ & Name ${ }^{a}$ & Sequence $5^{\prime} \rightarrow 3^{\prime}$ & Chimera & Truncating & Concentration $(\mu \mathrm{M})$ \\
\hline $\mathrm{P}$ & p53(1)22D & CCAGGCCTCTGATTCCTCACTG & No & No & 0.05 \\
\hline Q & p53(186)22U & СTTAАССССТССТСССАGAGAC & No & No & 0.1 \\
\hline $\mathrm{PC}$ & $C^{*} p 53(1) 22 D$ & CCAGGCCTCTGATICCTCACTG & Yes & Yes & $2^{c}$ \\
\hline $\mathrm{QC}^{2}$ & $C^{*} p 53(186) 22 U$ & 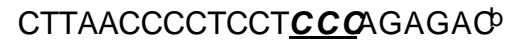 & Yes & Yes & $0.05^{c}$ \\
\hline $\mathrm{R}$ & p53(16)22D & TCACTGATTGCTCTTAGGTCTG & No & No & 0.1 \\
\hline $\mathrm{S}$ & p53(170)22U & AGAGACCCCAGTTGCAAACCAG & No & No & 0.1 \\
\hline \multicolumn{6}{|c|}{ 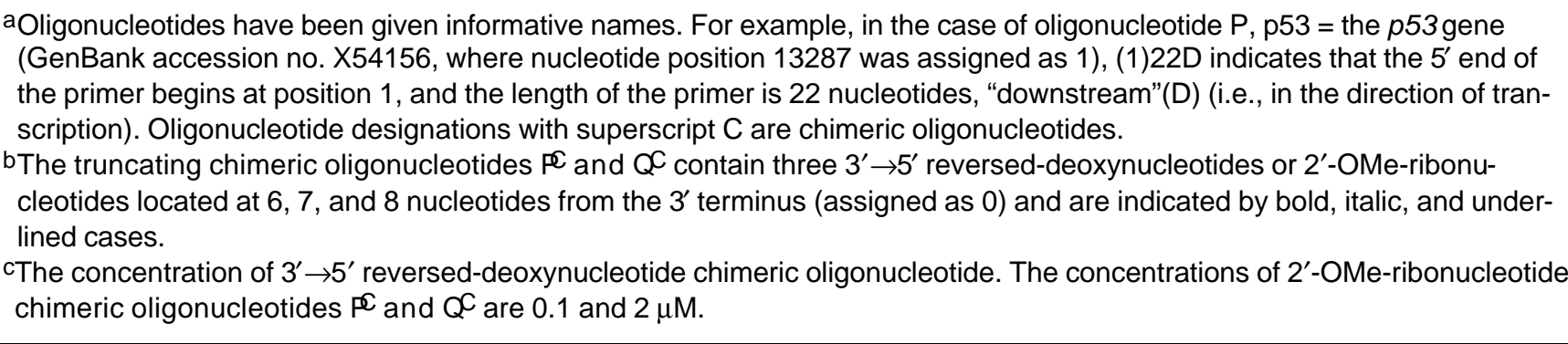 } \\
\hline
\end{tabular}

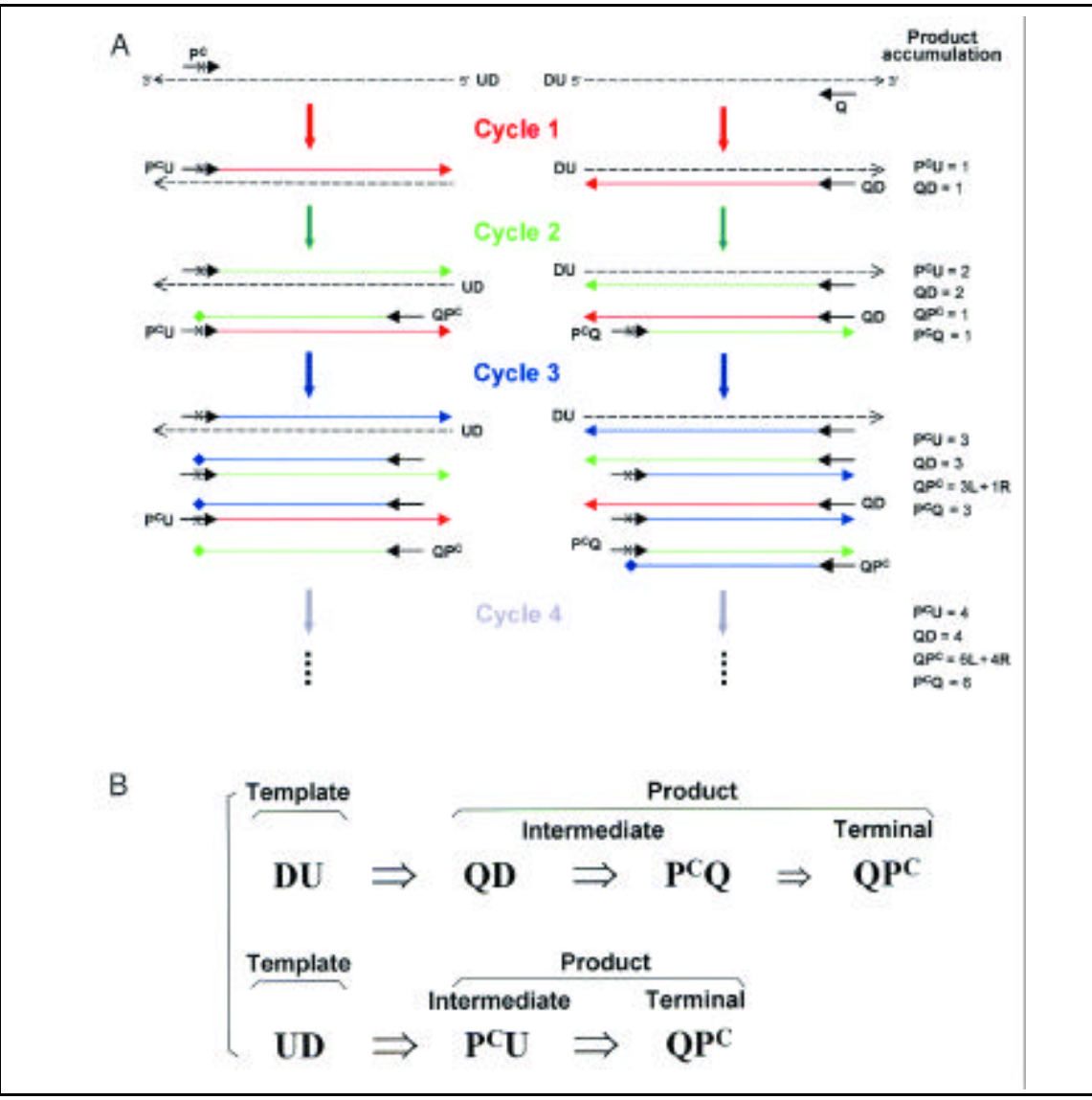

Figure 2. Principle of TA-g. (A) Schematic of TA-g. TA-g is performed with $\mathrm{P}^{\mathrm{C}}$ and $\mathrm{Q}$. $\mathrm{P}^{\mathrm{C}} \mathrm{U}(235$ bases), QD (221 bases), and $\mathrm{PC}^{\mathrm{C}}$ (186 bases) are the non-truncated intermediate products. $\mathrm{QPC}^{\mathrm{C}}(170$ bases) is the truncated terminal products. By cycle 4, the maximal product accumulations are $\mathrm{PC}^{C} \mathrm{U}=4$, $\mathrm{QD}=4, \mathrm{PQ}=6$, and $\mathrm{QP}^{\mathrm{C}}=10$. By 40 cycles, $\mathrm{P}^{\mathrm{C}} \mathrm{U}$ or $\mathrm{QD}=40, \mathrm{PC}^{\mathrm{Q}}=780$, and total $\mathrm{QPC}^{\mathrm{C}}=10699$. Alternatively, TA-g can be performed with $P$ and $\mathcal{Q}$ (not shown). (B) Flowchart of TA-g product accumulation. A branch of product accumulation derives from each of the original single-stranded templates in an asymmetric manner. There are four types of products. Segments $\mathrm{P}^{\mathrm{C}} \mathrm{U}$ (235 bases), QD (221 bases), and $\mathrm{P}^{\mathrm{C}} \mathrm{Q}$ (186 bases) are the intermediate products. Segment $\mathrm{QP}^{\mathrm{C}}$ (170 bases) is the terminal product. Alternatively, TA-g could be performed with $P$ and $Q$ (not shown).
The product was electrophoresed through an $8 \%$ polyacrylamide/7 M urea denaturing gel with $90 \mathrm{mM}$ TBE buffer or through an $8 \% \mathrm{HR}-1000^{\mathrm{TM}}$ (Genomyx, Foster City, CA, USA) nondenaturing SSCP gel with $30 \mathrm{mM}$ TRI/ TRI buffer (11). The gel was dried, and autoradiography was performed with Kodak $^{\circledR}$ X-OMAT ${ }^{\mathrm{TM}}$ AR film (Eastman Kodak, Rochester, NY, USA).

\section{Sequence Analysis}

The DU:UD template was amplified by TA using PfuTurbo DNA polymerase for 25 cycles, and then the product was purified using Microcon ${ }^{\circledR} 50$ microconcentrator (Amicon). Standard sequence analysis was performed using an $\mathrm{ABI} 377$ fluorescence sequencer and BigDye $^{\mathrm{TM}}$ terminator chemistry with AmpliTaq ${ }^{\circledR}$ FS DNA polymerase (Applied Biosystem). The two internal sequencing primers were p53(35)30D (5'CTGGCCCCTCCTCAGCATCTTATC CGAGTG-3') and p53(177)30U (5' TCCTCCCAGAGACCCCAGTTGCA AACCAGA-3'). The data were analyzed by Sequencher ${ }^{\mathrm{TM}}$ software (Gene Codes, Ann Arbor, MI, USA).

\section{RESULTS}

\section{Principle of TA}

The principle of TA-q and TA-g is indicated in Figures 1 and 2. TA-q uti- 
lizes two chimeric oligonucleotides, $\mathrm{PC}$ and $Q^{C}$ (Table 1). $P C$ and $Q^{C}$ have $3^{\prime} \rightarrow 5^{\prime}$ reversed-deoxyribonucleotides (creating $5^{\prime}$-to- $5^{\prime}$ and $3^{\prime}$-to- $3^{\prime}$ linkages) or 2'-OMe-ribonucleotides at 6-8 nucleotides from the $3^{\prime}$ terminus. The two original template strands produce four types of intermediate and truncated products (Figure 1). The extension products are terminal after two cycles of replication from the original tem plate. In the first cycle, the truncating chimeric oligonucleotides, $\mathrm{PC}^{\mathrm{C}}$ and $\mathrm{QC}$, are hybridized with the denatured single-strand templates UD and DU (each 270 bases in the model system utilized), respectively, and extended to generate the intermediate products $\mathrm{P}^{\mathrm{C}} \mathrm{U}$ and $Q^{C} D$ (235 and 221 bases). In the second cycle, $Q^{C}$ and $\mathrm{PC}^{\mathrm{C}}$ are hybridized with the templates ${ }^{C} C_{U}$ and $Q^{C} D$, respectively. They are extended to generate the truncated products ${ }^{C_{P C}}$ and $\mathrm{PCQC}^{\mathrm{C}}$ (each 170 bases) because the DNA polymerase is truncated by the nucleotide analogues of the templated ${ }^{\mathrm{C}} \mathrm{U}$ and $\mathrm{Q}^{\mathrm{C}} \mathrm{D}$. $\mathrm{Q}^{\mathrm{C}} \mathrm{P}$ and $\mathrm{PC}^{\mathrm{C}} \mathrm{Q}^{\mathrm{C}}$ are terminal products that cannot be used as templates for further amplification because they only have six nucleotides complementary to $\mathrm{PC}^{\mathrm{C}}$ and $\mathrm{QC}$. The products of TA-q accumulate approximately proportionally to the square of the number of cycles; the theoretical yield is shown in Figure 3A.

TA-g utilizes one chimeric oligonucleotide and one regular oligonucleotide. Four types of intermediate and terminal products are produced in an asymmetric manner (Figure 2). The $\mathrm{QPC}^{\mathrm{C}}$ products are terminal after two or three cycles of replication from the original template. In the first cycle, $\mathrm{P}^{\mathrm{C}}$ and $\mathrm{Q}$ are hybridized with UD and DU, respectively. They are extended to generate the intermediate products $\mathrm{PC}^{\mathrm{C}} \mathrm{U}$ and QD (235 and 221 bases). In the second cycle, $\mathrm{Q}$ is hybridized with $\mathrm{P}^{\mathrm{C}} \mathrm{U}$ and is extended to generate a truncated product $\mathrm{QPC}$ (170 bases); $\mathrm{PC}$ is hybridized with QD and is extended to generate the intermediate product $\mathrm{PC}^{\mathrm{Q}} \mathrm{Q}(186$ bases) (Figure 1C). In the third cycle, $\mathrm{Q}$ is hybridized with $\mathrm{PC}^{\mathrm{C}} \mathrm{Q}$ and is extended to generate the truncated product $\mathrm{QPC}$ (170 bases). In this way, $\mathrm{QPC}$ product can accumulate preferentially and DU strand is predominantly amplified (Figure $3 \mathrm{~B}$ ). Thus, the essence of TA is the accumulation of truncated and terminal products from no more than three cycles of replication of the original template.

\section{TA of the p53 Gene}

The DU:UD (270 bp) duplexed tem plate of exon 6 of the $p 53$ gene was am plified using PfuTurbo DNA polymerase (Figure 4). For TA-q performed with $\mathrm{PC}^{\mathrm{C}}$ and $\mathrm{QC}$, the truncated products $\mathrm{P}^{\mathrm{C}} \mathrm{Q}^{\mathrm{C}}$ and $\mathrm{Q}^{\mathrm{C}} \mathrm{C}$ (each 170 bases) were generated. There is no product of 186 bases, indicating PfuTurbo DNA polymerase could not pass through the re- versed-deoxyribonucleotides on the templated chimeras $\mathrm{PC}$ and $\mathrm{Q}$. For TA-g with $\mathrm{P}$ and $\mathrm{Q}$, the intermediate product QP (186 bases) and the truncated product PQC (170 bases) were generated. For another possible TA-g with $\mathrm{PC}$ and $\mathrm{Q}$, the intermediate product $\mathrm{PC}^{\mathrm{Q}}$ (186 bases) and the truncated product QPC (170 bases) were generated.

A shortened template, RS:SR (154 bp), was designed to test that the truncated product is terminal (Figure 4). RS and SR strands have only six $3^{\prime} \mathrm{nu}-$ cleotides complementary to $\mathrm{Q}^{\mathrm{C}}$ and $\mathrm{PC}$, respectively. They have the same nu-
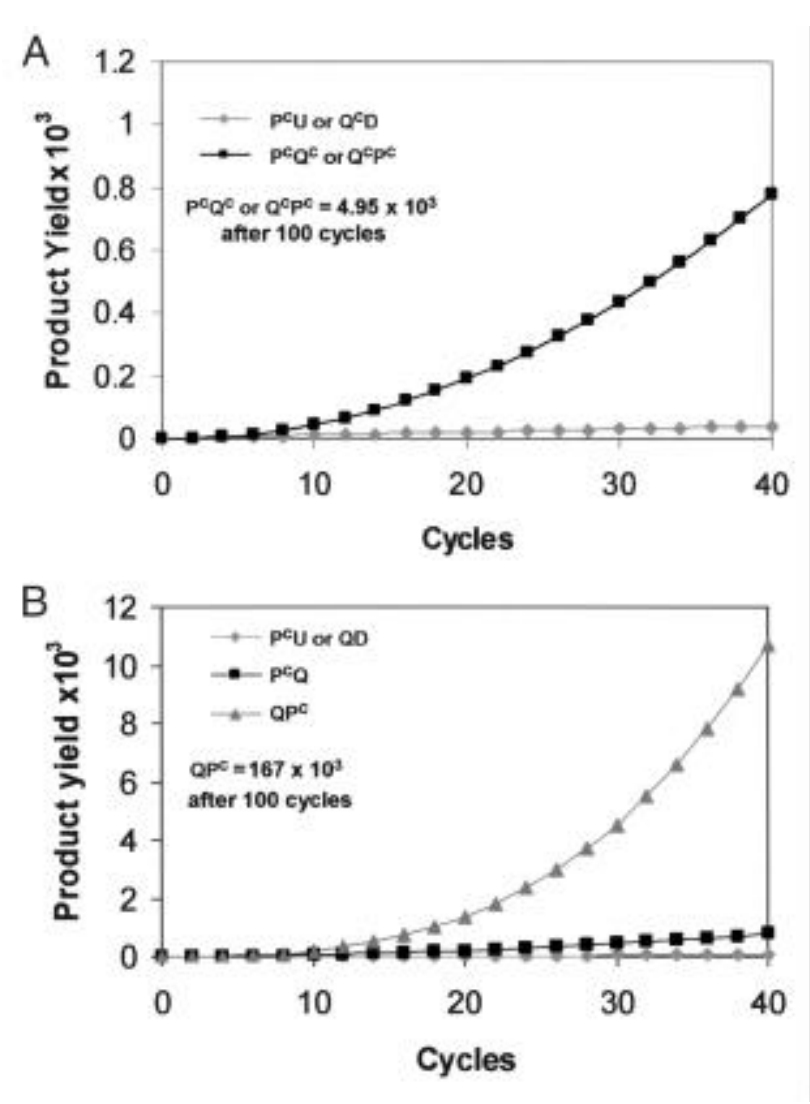

Figure 3. Theoretical accumulation of products during TA-q (A) and TA-g (B). The maximum num ber of product molecules amplified from a single-stranded template (y-axis) is plotted relative to the number of cycles (x-axis) using PC and $Q$ for TA-q (A) or using PC and Q for TA-g (B). TA-q. The amount of PCU or $Q \mathrm{D}=\mathrm{C} \times \lambda \times n$, where $\mathrm{C}$ is the amount of the original single-stranded template (downstream $=$ upstream), $n$ is the total number of cycles, and $\lambda$ is the amplification efficiency [the ratio of the newly synthesized strand to the template strand $(0 \leq \lambda \leq 1)]$. The amount of $\mathrm{PCQC}^{\mathrm{C}}$ or $\mathrm{QCPC}^{\mathrm{P}}=1 / 2 \times$ $\mathrm{C}_{0} \times \lambda^{2} \times n \times(n-1)$. The total amount of the four single-stranded products $=C \times\left[2 \times \lambda \times n+\lambda^{2} \times n \times(n-\right.$ 1)]. It is assumed that $P C, Q C, P$, and $Q$ have the same $\lambda$, and $\lambda$ is constant with cycling. The total number of accumulated product molecules is the addition of all the types. With increasing cycles, $\mathrm{PCQC}^{\mathrm{C}}$ and QCPC terminal products accumulate approximately proportional to $n^{2}$. TA-g. The amount of PCU or QD $=\mathrm{C}_{0} \times \lambda \times n$, the amount of $\mathrm{PCQ}$ or QPC from UD strand $=1 / 2 \times 6 \times \lambda 2 \times n \times(n-1)$, the amount of $\mathrm{QPC}$ from DU strand $=1 / 2 \times 6 \times \lambda^{3} \times[(n-1)(n-2)+(n-2)(n-3)+(n-3)(n-4)+\ldots+2 \times 1]$. The total amount of the single-stranded products $=C_{0} \times\left\{2 \times \lambda \times n+\lambda^{2} \times n \times(n-1)+1 / 2 \times \lambda^{3} \times[(n-1)(n-2)+(n-2)(n-3)+(n-\right.$ $3)(n-4)+\ldots+2 \times 1]\}$. With increasing cycles, terminal product $\mathrm{QPC}$ from DU strand accumulates approximately proportional to $n^{3}$ and dominates. 
cleotide sequences as $\mathrm{P}^{\mathrm{C}} \mathrm{Q}^{\mathrm{C}}$ or $\mathrm{PQ}$ and as $\mathrm{QP}^{\mathrm{C}}$ or $\mathrm{QPC}$. No products were produced by TA, indicating the truncated product is the terminal product. Two other shortened templates, PS:SP (170 bp) and RQ:QR (170 bp), were also tested. PS and QR strands contain the same nucleotide sequences as $\mathrm{PC}^{\mathrm{C}}$ and $\mathrm{Q}^{\mathrm{C} P}$, respectively. Again, no products were amplified by TA from any of the shortened templates (data not shown).

$\mathrm{P}^{\mathrm{C}} \mathrm{Q}$ and $\mathrm{P}^{\mathrm{C}} \mathrm{Q}^{\mathrm{C}}$ can be separated from $\mathrm{QPC}^{\mathrm{C}}$ and $\mathrm{QC}^{\mathrm{C} C}$ (each 170 bases), and $\mathrm{PC}^{\mathrm{C}}$ can be separated from $\mathrm{QCP}$ (each 186 bases) on a nondenaturing SSCP gel (Figure 4B). The sense and antisense strands of the same size could not be separated on a denaturing gel (Figure 4C). In the experiments for Figure $4, \mathrm{~B}$ and $\mathrm{C}$, the double-stranded products were also seen. They are due to hybridization among the singlestranded molecules in the electrophoresis because the double-stranded products did not appear on a more powerful denaturing gel containing $40 \%$ formamide and $7 \mathrm{M}$ urea (data not shown).

The TA products were further analyzed by ABI fluorescent sequence analysis with internal primers in the downstream and upstream directions. The sequence result shows the correct sequences and truncated sites (Figure 5), confirming that the TA products were as thought and demonstrating that AmpliTaq FS DNA polymerase extends through the modified nucleotides at a low rate.

\section{Effect of DNA Polymerase}

The DU:UD (270 bp) template was amplified by PfuTurbo, Taq, and Vent (exo-) DNA polymerases. Taq and Vent $\left(\mathrm{exo}^{-}\right)$can partially read through the analogue nucleotides of the templated chimeras, but not PfuTurbo (Figure 6). For TA-q with $\mathrm{PC}^{\mathrm{C}}$ and $\mathrm{Q}^{\mathrm{C}}$, the truncated products $\mathrm{PC}^{\mathrm{C}}$ and $\mathrm{QCPC}^{\mathrm{C}}$ (each 170 bases) were generated. However, the full length products (186 bases) were also generated by reading through the analogous nucleotides by Taq and Vent $\left(\mathrm{exo}^{-}\right)$DNA polymerases. For TA-g with $P$ and $Q C$, the intermediate product QCP (186 bases) and the truncated product $\mathrm{PQ}$ ( 170 bases) were generated. However, the full-length products were also generated. In the comple- mentary TA-g with $\mathrm{PC}^{\mathrm{C}}$ and $\mathrm{Q}$, the intermediate product $\mathrm{PC}^{\mathrm{Q}}$ (186 bases) and the truncated product $\mathrm{QPC}$ (170 bases) were generated, but the full-length products were also generated.

\section{Effect of Chimeras Containing 2'-OMe-Ribonucleotides}

The above experiments were performed with other truncating chimeras that contain three successive $2^{\prime}$-OMeribonucleotides at six, seven, and eight nucleotides from the $3^{\prime}$ terminus (Table 1). The results were similar in that $P f u$ Turbo DNA polymerase could not read through the modified nucleotides on the template, but Taq, Vent (exo-), and AmpliTaq FS could partially extend through the modified nucleotides (data not shown).

\section{DISCUSSION}

We demonstrate proof of principle for truncating amplification with $P f u$ Turbo DNA polymerase and truncating chimeric oligonucleotides. The effect of PfuTurbo, Taq, and Vent (exo-) DNA polymerases with the two chimeric oligonucleotides containing $3^{\prime} \rightarrow 5^{\prime}$ re-
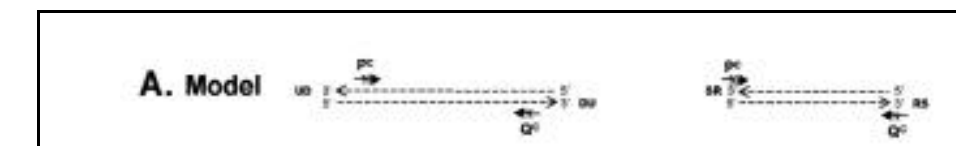

\section{B. Nondenaturing gel}
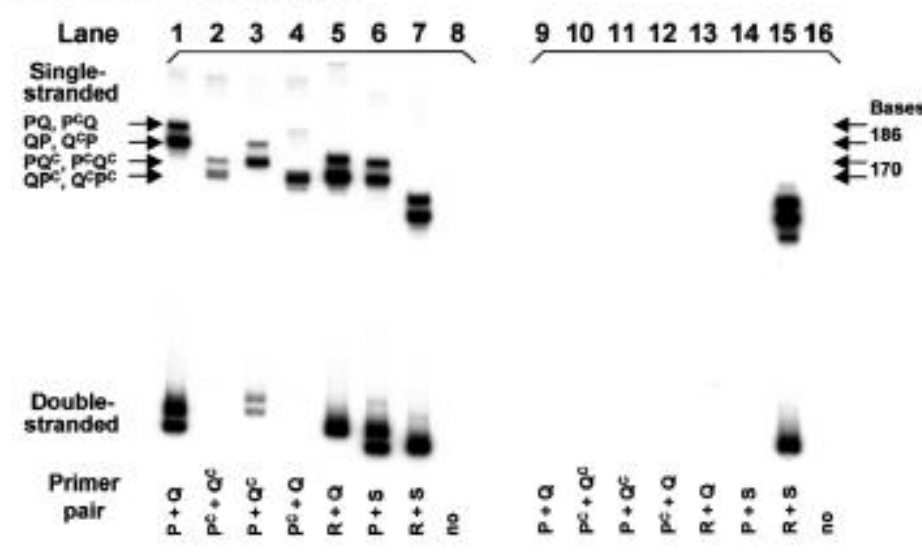

\section{Denaturing gel}

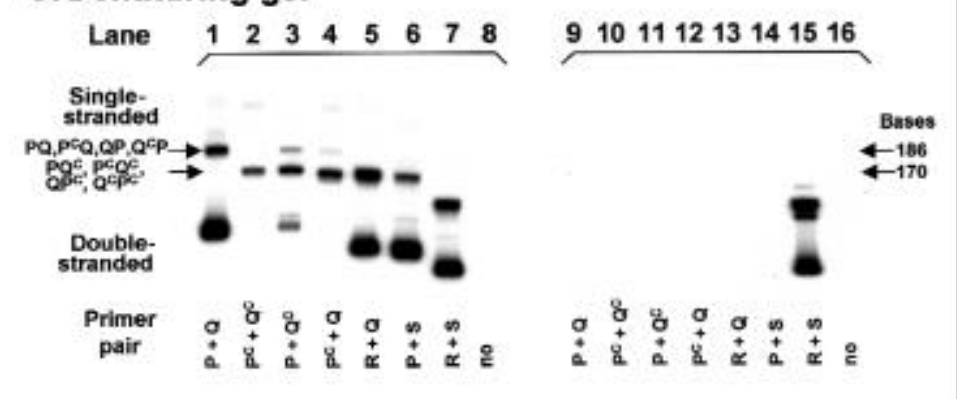

Figure 4. TA of the $p 53$ gene. (A) DU:UD (270 bp) is the duplexed template used in lanes 1-8. RS:SR (154 bp) is the shortened duplexed template used in lanes 9-16 (Materials and Methods). RS and SR strands have only six $3^{\prime}$ nucleotides complementary to $\mathscr{C}$ and PC. The two above templates were amplified with seven sets of primer pairs (Figure 4B). After amplification, the products were electrophoresed through a nondenaturing and a denaturing gel. (B and C) Autoradiograms of an 8\% HR1000 nondenaturing SSCP gel and an $8 \%$ polyacrylamide/7 M urea denaturing gel, respectively. When the template DU:UD is used, lanes 1, 5, 6, and 7 are control PCRs that generate size markers. Lane 2 is TA-q with PC and $Q$. Lanes 3 and 4 are TA-g with $P$ and $Q \mathcal{C}$ and TA-g with PC and Q, respectively. When the shortened template RS: SR is used, no TA amplification occurs in lanes 10,11, and 12, demonstrating that the putative terminal truncated products do not support amplification. Lanes 9, 13, 14, and 15 are PCR controls. Lanes 8 and 16 are negative controls with no primers. 


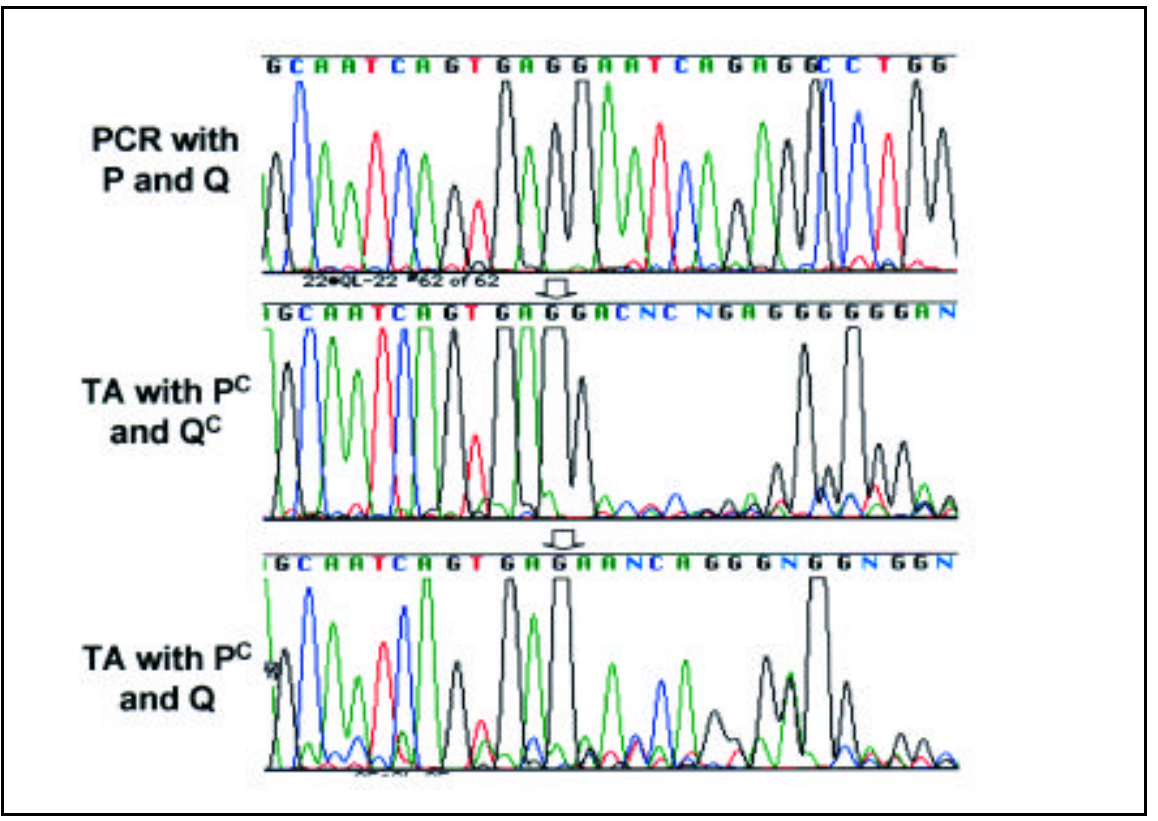

Figure 5. Sequence analysis of TA products. The TA products amplified with $\mathrm{PC}$ and $\mathrm{QC}$ and $\mathrm{PC}$ and $\mathrm{Q}$ were sequenced with the internal upstream primer in comparison with PCR product with P and Q. Arrow indicates the truncation site. versed deoxyribonucleotides and $2^{\prime}$ OMe-ribonucleotides was explored. PfuTurbo DNA polymerase could not read through the modified nucleotides on the template, but Taq, Vent (exo-), and AmpliTaq FS could partially extend through the modified nucleotides. It was reported that some DNA polymerases, such as Taq, have reverse transcription activity and can use a RNA template for extension $(8,24)$.

More work is required to realize the potential for TA to meet robustly the challenge of amplifying from single cells. Time will tell if amplification with chimeric oligonucleotides is a useful approach for one or more applications, including those suggested below. These initial experiments indicate that more experience is needed to determine the parameters required for primers of reproducible efficiency. For example, one of the $3^{\prime} \rightarrow 5^{\prime}$ reversed chimeric oligonucleotide, $\mathrm{PC}$, has a low efficien- 
cy, requiring concentration 20-fold higher than the other primer, $\mathcal{Q}$. In contrast, the other 2'-OMe-ribonucleotide chimeric oligonucleotide, $\mathbb{Q}$, has low efficiency. The optimal type, location, and number of nucleotide analogues must be determined. Chimeric polyamide nucleic acid-DNA oligonucleotides lacking the phosphate backbone (17) have the potential to truncate all DNA polymerases, allowing DNA polymerase without $3^{\prime} \rightarrow 5^{\prime}$ exonuclease (e.g., Taq) to be utilized.

\section{TA versus PCR}

There are many applications for which PCR is the method of choice because of convenience of the existing infrastructure of established protocols and, most importantly, the greater than 1 million-fold amplification readily achieved. However, in commercial situations, the application of PCR may be prohibited or not optimal because of licensing or royalty considerations. Hence, there is interest in alternative forms of amplification $(1,2,5,9,10,12$, 15). TA is such an alternative method that retains two important aspects of PCR: the flexibility of amplification of any sequence and the convenience of automation by thermal cycling.

In the broadest patent claim, PCR is envisioned as an exponential process in which the products generated in each cycle are templates for amplification in subsequent cycles (18). TA retains certain features of PCR, such as the use of a pair of opposite primers and automation by thermal cyclers, but it differs from PCR in important ways: (i) TA uses truncating chimeric oligonucleotides; (ii) TA produces truncated terminal products that are not templates for further amplification; (iii) TA amplifies quadratically or geometrically; (iv) the products are never more than three rounds of replication from the original template, providing more error-free products by dramatically limiting the propagation of DNA polymerase errors; and ( $v)$ in TA-g, primers of equal concentration produce an asymmetric amplification. The excess of single-stranded product produced by TA-g may be advantageous for probes in other analyses. In asymmetric PCR, the amount of excess single-stranded product is hard to control because it varies dramatically with template and primer concentrations. TA-g is a more robust method of asymmetric amplification than asymmetric PCR in which a single-stranded product is amplified preferentially through an exponential and a linear stage using unequal amounts of primers (6).

\section{Potential Applications of TA}

TA was developed to reduce allele dropout from single-cell amplifications and to increase the fidelity of DNA polymerase during the amplification process. The first few rounds of amplification from single cells are critical.
Once hundreds to thousands of products have been made, PCR or other am plification methods can be used subsequently. Provided that the great majority of product is of correct sequence and both alleles are present in roughly equal amounts, the higher error rate of a subsequent PCR will not affect the results of a sequence analysis.

TA-g is expected to have a maximum of greater than 10000-fold amplification after 40 cycles and greater than 100000 -fold amplification after 100 cycles. If TA is used for enhanced fidelity from genomic DNA (e.g., $1 \mu \mathrm{g}$ ), then the amount of amplified product is well within the detection limits of different procedures.

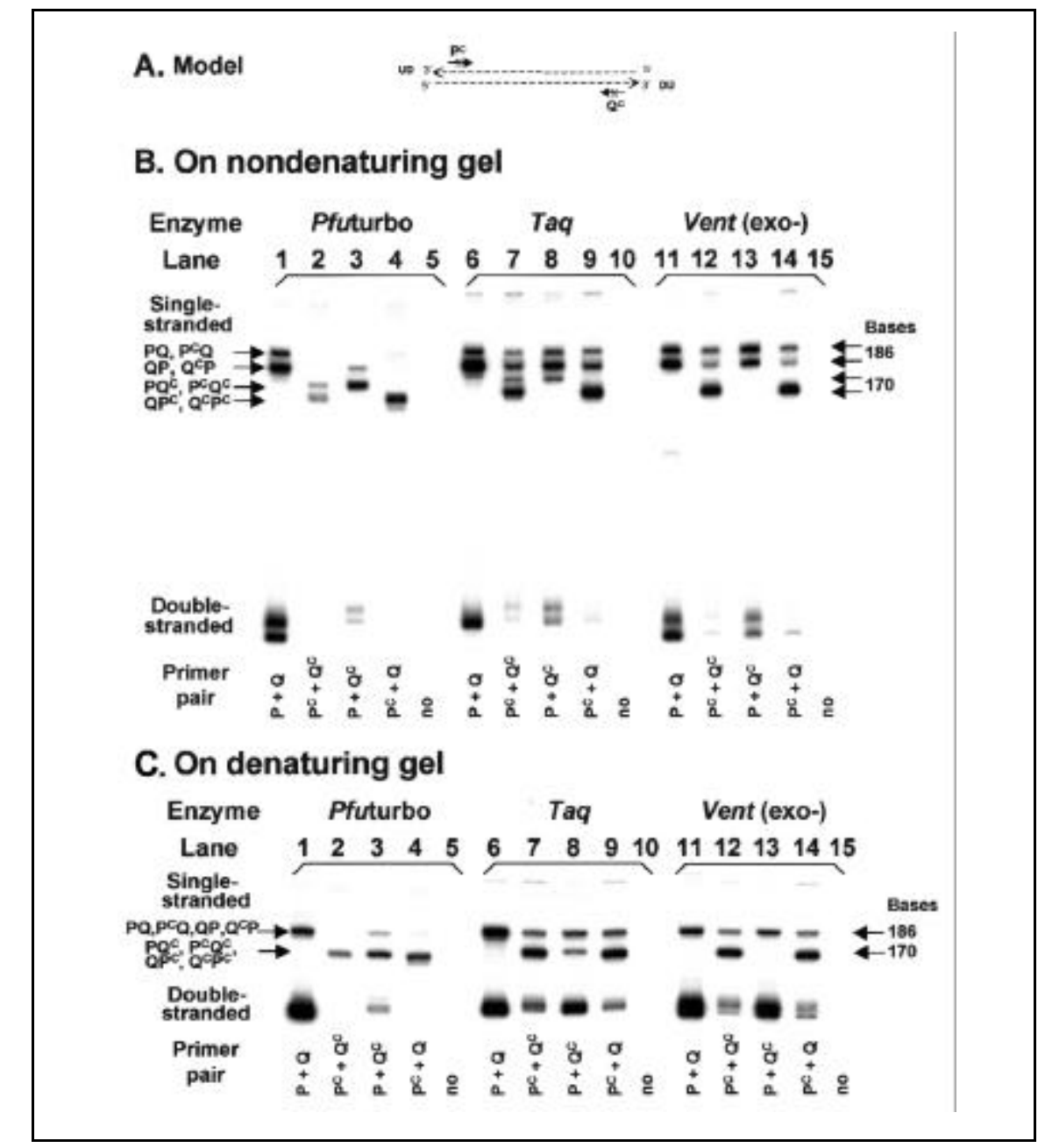

Figure 6. Effect of DNA polymerase. (A) The DU:UD duplexed template (270 bp) is used. (B and C) Autoradiograms of an 8\% HR1000 nondenaturing SSCP gel and an 8\% polyacrylamide/7 M urea denaturing gel. PfuTurbo, Taq, and Vent (exo-) DNA polymerases were used in lanes 1-5, lanes 6-10, and lanes 11-15, respectively. Lanes 2, 7, and 12 are TA-q with $\mathrm{PC}^{\mathrm{C}}$ and $\mathrm{Q}^{\mathrm{C}}$. Lanes 3, 8, and 13 are TA-g with $\mathrm{P}$ and $\mathrm{Q}$. Lanes 4, 9, and 14 are TA-g with $\mathrm{PC}^{\mathrm{C}}$ and $\mathrm{Q}$. Lanes 1, 6, and 11 are PCR controls. Lanes 5, 10, and 15 are negative controls with no primers. 
With the recent advent of practical high-output in vitro translation system (Rapid Translation System 500; Roche Applied Science), amplification of cDNA segments followed by in vitro transcription/translation can generate milligrams of proteins for structural and functional analysis, including protein crystallography. During the development of protein drugs, it may be advantageous to determine amino acid sequences by analyzing the amino- or carboxy-terminus of the protein, but it is necessary for most of the amplified products to be completely error-free. TA should substantially increase the number of error-free products. For instance, using a DNA polymerase with an error rate of $10^{-4}$ to amplify a 200-bp segment with $100 \%$ amplification efficiency, the PCR-induced error constitutes as much as $33 \%$ of the 1 millionfold amplified products (3); however, TA-q- and TA-g-induced errors are calculated to be $3.9 \%$ and $5.8 \%$ of the am plified products by the end of $100 \mathrm{cy}$ cles, respectively. For a 2-kb segment, the PCR-induced error constitutes 98.2 $\%$ of the 1 million-fold amplified products (3), but TA-q and TA-g induced errors are calculated to be $35.6 \%$ and $47.4 \%$ of the amplified products by the end of 100 cycles, respectively. The frequency of TA-induced error is not affected by the amount of starting tem plate or the number of cycles.

RNA amplification with in vitro translation, which was described as a PCR protocol (23), can be adapted to TA. With the advent of highly parallel synthesis of oligonucleotides, RNA amplification with in vitro translation can generate the above-mentioned protein derivatives in a very rapid manner, with the advantage that substantially more of the products for in vitro translation are error-free.

The exponential nature of PCR amplification can generate a great deal of product. However, this can be problem atic for quantitative PCR, because small variations in efficiency per cycle can have dramatic effects on the yields after a typical 30 cycles (13). This limitation is substantial in clinical practice since large heterozygous deletions in patients are commonly missed because only 2-fold differences in template concentrations are difficult to detect.
The quadratic and geometric nature of TA should be better suited for quantitative measurements.

TA-g can be used for preferential amplification of only one specific strand of the duplexed template to analyze strand-specific events, such as adduct or DNA damage (20), and to perform Sanger sequencing (22) or sequencing by hybridization $(7,16,25)$. TA can be combined with bidirectional denaturing fingerprinting (14).

\section{REFERENCES}

1.Banér, J., M. Nilsson, M. Mendel-Hartvig, and U. Landegren. 1998. Signal amplification of padlock probes by rolling circle replication. Nucleic Acids Res. 26:5073-5078.

2.Barany, F. 1991. Genetic disease detection and DNA amplification using cloned thermostable ligase. Proc. Natl. Acad. Sci. USA 88:189-193.

3.Cha, R.S. and W.G. Thilly. 1995. Specificity, efficiency and fidelity of PCR, p. 37-51. In C.W. Dieffenbach and G.S. Dveksler (Eds.), PCR Primer-A Laboratory Manual. CSH Laboratory Press, Cold Spring Harbor, NY.

4.Gait, M.J. 1984. Oligonucleotide Synthesis: A Practical Approach. IRL Press, Oxford, Washington, D.C.

5.Guatelli, J.C., K.M. Whitfield, D.Y. Kwoh, K.J. Barringer, D.D. Richman, and T.R. Gingeras. 1990. Isothermal, in vitro amplification of nucleic acids by a multienzyme reaction modeled after retroviral replication. Proc. Natl. Acad. Sci. USA 87:1874-1878.

6.Gyllensten, U.B. and H.A. Erlich. 1988. Generation of single-stranded DNA by the polymerase chain reaction and its application to direct sequencing of the $H L A-D Q A$ locus. Proc. Natl. Acad. Sci. USA 85:7652-7656.

7.Hacia, J.G. and F.S. Collins. 1999. Mutational analysis using oligonucleotide microarrays. J. Med. Genet. 36:730-736.

8.Jones, M.D. and N.S. Foulkes. 1989 Reverse transcription of mRNA by Thermus aquaticus DNA polymerase. Nucleic Acids Res. 17:8387-8388.

9.Kramer, F.R. and P.M. Lizardi. 1989. Replicatable RNA reporters. Nature 339:401-402.

10.Landegren, U., R. Kaiser, J. Sanders, and L. Hood. 1988. A ligase-mediated gene detection technique. Science 241:1077-1080.

11.Liu, Q., X. Li, and S.S. Sommer. 1999. pkmatched running buffers for gel electrophoresis. Anal. Biochem. 270:112-122.

12.Liu, Q. and S.S. Sommer. 2000. Pyrophosphorolysis activated polymerization (PAP): application to allele-specific amplification. BioTechniques. 29:1072-1080.

13.Liu, Q., E.C. Thorland, and S.S. Sommer. 1997. Inhibition of PCR amplification by a point mutation downstream of a primer. BioTechniques 22:292-298.

14.Liu, Q., B.G. Weinshenker, D.M. Wingerchuk, and S.S. Sommer. 1998. Denaturation fingerprinting: two related mutation detection methods especially advantageous for high
$\mathrm{G}+\mathrm{C}$ regions. BioTechniques 24:140-147.

15.Lizardi, P.M., X. Huang, Z. Zhu, P. BrayWard, D.C. Thomas, and D.C. Ward. 1998. Mutation detection and single-molecule counting using isothermal rolling-circle amplification. Nat. Genet. 19:225-232.

16.Lysov, I., V.L. Florent'ev, A.A. Khorlin, K.R. Khrapko, and V.V. Shik. 1988. Determination of the nucleotide sequence of DNA using hybridization with oligonucleotides. A new method. Dokl. Akad. Nauk. SSSR 303:1508-1511.

17.Misra, H.S., P.K. Pandey, M.J. Modak, R. Vinayak, and V.N. Pandey. 1998. Polyamide nucleic acid-DNA chimera lacking the phosphate backbone are novel primers for polymerase reaction catalyzed by DNA polymerases. Biochemistry 37:1917-1925.

18.Mullis, K.B., inventor; Cetus, assignee. Process for amplifying nucleic acid sequences. US Patent 4683 202. 1987 July 28.

19.Persson, A.E., G. Ling, C. Williams, H. Backvall, J. Ponten, F. Ponten, and J. Lundeberg. 2000. Analysis of p53 mutations in single cells obtained from histological tissue sections. Anal. Biochem. 287:25-31.

20.Pfeifer, G.P., H.H. Chen, J. Komura, and A.D. Riggs. 1999. Chromatin structure analysis by ligation-mediated and terminal transferase-mediated polymerase chain reaction. Methods Enzymol. 304:548-571.

21.Saiki, R.K., S. Scharf, F. Faloona, K.B. Mullis, G.T. Horn, H.A. Erlich, and N. Arnheim. 1985. Enzymatic amplification of $\beta$-globin genomic sequences and restriction site analysis for diagnosis of sickle cell anemia. Science 230:1350-1354.

22.Sanger, F., S. Nichlen, and A.R. Coulson. 1977. DNA sequencing with chain-terminating inhibitor. Proc. Natl. Acad. Sci. USA 75:54635467.

23.Sarkar, G. and S.S. Sommer. 1989. Access to a messenger RNA sequence or its protein product is not limited by tissue or species specificity. Science 244:331-334.

24.Shibata, H., T. Tahira, and K. Hayashi. 1995. RNA-primed PCR. Genome Res. 5:400403.

25.Southern, E.M., U. Maskos, and J.K. Elder. 1992. Analyzing and comparing nucleic acid sequences by hybridization to arrays of oligonucleotides: evaluation using experimental models. Genomics 13:1008-1017.

26.Swiderski, P.M., E.L. Bertrand, and B.E. Kaplan. 1994. Polystyrene reverse-phase ionpair chromatography of chimeric ribozymes. Anal. Biochem. 216:83-88.

Received 19 September 2001; accepted 4 February 2002.

\section{Address correspondence to:}

Dr. Steve S. Sommer

Director, Departments of Molecular Genetics and Molecular Diagnosis

City of Hope National Medical Center

1500 East Duarte Road

Duarte, CA 91010-3000, USA

e-mail:ssommer@coh.org 